\title{
MASCULINIDADES E PSICANÁLISE: UMA REVISÃO DE LITERATURA
}

\section{ARTIGO DE REVISÃO}

SILVA, Alessandra Maria Cardoso da ${ }^{1}$, PRIOSTE, Cláudia Dias²

SILVA, Alessandra Maria Cardoso da. PRIOSTE, Cláudia Dias. Masculinidades e psicanálise: uma revisão de literatura. Revista Científica Multidisciplinar Núcleo do Conhecimento. Ano 06, Ed. 05, Vol. 11, pp. 55-79. Maio de 2021. ISSN: 2448-0959, Link de acesso:

https://www.nucleodoconhecimento.com.br/psicologia/masculinidades-e-psicanalise, DOI: 10.32749/nucleodoconhecimento.com.br/psicologia/masculinidades-epsicanalise

\section{RESUMO}

A temática da masculinidade tem sido alvo de pesquisas brasileiras, com aumento significativo de publicações a partir da década de 2000. No entanto, no âmbito da psicanálise, ainda são escassas as investigações sobre masculinidade, se comparada às questões femininas. Assim, o presente artigo apresenta os resultados de uma revisão sistemática de literatura que teve o objetivo de compreender como a psicanálise tem sido utilizada para interpretar as questões pertinentes à masculinidade. Trata-se de uma pesquisa descritiva-exploratória realizada a partir dos descritores "psicanálise" e "masculinidade", focada em artigos publicados no Brasil nos últimos dez anos, com análise temática e qualitativa dos dados. Os resultados identificaram que a psicanálise aparece basicamente em três

\footnotetext{
${ }^{1}$ Mestranda pelo programa de Pós-graduação em Educação Sexual, Universidade Estadual Paulista, Unesp/Fclar. Especialização em andamento em Formação Didático Pedagógica para à Educação à Distância, Universidade Virtual do Estado de São Paulo, UNIVESP, Brasil; Graduação em Psicologia, Centro Universitário Salesiano São Paulo, UNISAL, Brasil.

${ }^{2}$ Orientadora. Doutora pelo Programa de Pós-Graduação em Educação, Universidade de São Paulo, USP; Mestre pelo Programa de Pós-Graduação em Educação, Universidade de São Paulo, USP; Graduação em Psicologia pelo Centro Universitário Paulistano, UniPaulistana.
}

RC: 85791

Disponível

em: https://www.nucleodoconhecimento.com.br/psicologia/masculinidades-epsicanalise 
perspectivas: a) nas discussões ampliadas e tensionada sobre gênero, sem especificar a masculinidade; b) de maneira transversal aos estudos de gênero direcionados à masculinidade; c) como foco central sobre a masculinidade contemporânea. Nesta última perspectiva foram encontrados somente três artigos, sendo apenas um decorrente de estudo empírico, cujo enfoque foi o padecimento psíquico de homens escutados na clínica psicanalítica. Concluiu-se que a psicanálise tem sido um importante referencial em estudos de gênero que abordam temáticas da masculinidade, ainda que apresente tensões e conflitos com outras áreas do conhecimento. Identificou-se, assim, a relevância da psicanálise nos caminhos argumentativos para leituras interdisciplinares sobre 0 tema das masculinidades.

Palavras-chave: masculinidade, psicanálise, gênero.

\section{INTRODUÇÃO}

A psicanálise teve como marco inaugural as investigações sobre a histeria que, inicialmente, vinculava-se a um conjunto de sintomas atribuídos, sobretudo às mulheres e que, posteriormente, foram ampliadas para outras sintomatologias da vida psíquica. As questões pertinentes ao universo feminino, com toda sua complexidade, foram, no final do século XIX disparadoras de análises aprofundadas sobre o funcionamento psíquico e sua vinculação à sexualidade. No entanto, de acordo com Sampaio e Garcia (2010) para a psicanálise, o interesse secular em desvendar a singularidade feminina não tem "um movimento semelhante em relação aos homens, assim, o homem tendeu a ser compreendido como sendo mais simples e menos misterioso, apresentando um processo de constituição subjetiva teoricamente menos engenhoso" (SAMPAIO e GARCIA, 2010, p. 82). A sexualidade masculina $\mathrm{e}$ as particularidades das masculinidades engendradas em diferentes contextos sociais foram, em certa medida, negligenciadas em decorrência, principalmente, do mito da menor complexidade. 
Na década de 1960, com a ampliação dos movimentos feministas e o acirramento dos debates sobre gênero e sexo, o mito da masculinidade menos complexa passou a ser questionado no âmbito da psicanálise. Assim, nas últimas décadas, investigações sobre os homens e as constituições das subjetividades masculinas, pautadas pela abordagem teórica da psicanálise, começaram a ser difundidas nos Estados Unidos, e foram recorrentes em pesquisas na Europa e no Brasil (SAMPAIO e GARCIA, 2010).

No âmbito da sociologia, Giddens (2007) destacou a escassez de estudos sobre as formações identitárias da masculinidade. Em sua visão, historicamente "pouco se fez para analisar a masculinidade, a experiência de se ser homem ou a formação das identidades masculinas. Os sociólogos preocupavam-se mais em compreender a opressão dos homens sobre as mulheres e o seu papel na manutenção do patriarcado" (GIDDENS, 2007, p. 120). Contudo, a partir da década de 80 , com mudanças substanciais nos papéis que afetavam as mulheres e os padrões de família nas sociedades industrializadas, alguns questionamentos passaram a pautar reflexões sobre a natureza da masculinidade. Neste sentido, identificam-se maiores investigações sobre os significados de ser homem na sociedade contemporânea, e como estes significados foram sendo construídos ao longo da história (GIDDENS, 2007).

Feminilidade e masculinidade na sociologia e na antropologia dos sexos "designam as características e as qualidades atribuídas social e culturalmente aos homens e às mulheres. Masculinidade e feminilidade existem e se definem em sua relação e por meio dela" (MOLINIER; WELZER-LANG, 2009, p. 101). A concepção de masculinidade também tem sido intrinsecamente associada ao conceito de virilidade, no sentido de um conjunto de atributos sociais vinculados ao homem e que incluem força, coragem, direito à violência, dominação, privilégios, além da forma erétil do órgão sexual. 
O interesse sobre o tema da constituição das subjetividades masculinas também está vinculado ao que tem sido denominado "masculinidade tóxica". Sculos (2017, n.p) define o termo masculinidade tóxica como um "conjunto de normas, crenças e comportamentos associados à masculinidade e que são prejudiciais às mulheres, homens, crianças e à sociedade em geral". O autor também considera que o termo:

O termo 'tóxico' expressa a nocividade das práticas e discursos que compõem essa noção de masculinidade [...] incluem: hipercompetitividade, auto-suficiência, individualismo [...], tendência ou glorificação da violência (real ou digital, direcionada a pessoa ou a qualquer ser vivo ou não vivo), chauvinismo (paternalismo em relação às mulheres), sexismo (superioridade), misoginia (ódio às mulheres), concepções rígidas de identidade e papéis sexuais / de gênero, heteronormatividade (crenças na naturalidade $e$ superioridade da heterossexualidade cisgênica), direito à atenção (sexual) das mulheres, objetificação (sexual) das mulheres, infantilização das mulheres (tratando-as como imaturas, sem consciência, esperando mansidão ou desejando que tenham sempre uma aparência jovem). (SCULOS, 2017, n.p. tradução nossa).

Percebe-se que as práticas nocivas se dirigem aos próprios homens e à sociedade em geral, o que corrobora com os fatores de risco que se dão em três direções segundo a Organização Panamericana de Saúde/Organização Mundial da Saúde (OPS/OMS, 2019, p.4):

1) Em relação a mulheres e crianças (violência, abuso de substâncias psicoativas, infecções sexualmente transmissíveis, gravidez forçada, paternidade ausente e falta de corresponsabilidade no lar). 2) Em relação a outros homens (acidentes, homicídios e outros, transmissão de HIV / AIDS). 3) Em relação a si mesmo (suicídio, acidentes, alcoolismo e vícios e doenças psicossomáticas). (OPS/OMS,2019, p.4, tradução nossa[3]).

Neste sentido, os fatores de risco associados à socialização masculina tóxica se constituem por uma tríade de comportamentos prejudiciais, partindo dos homens: em relação às mulheres, crianças, a outros homens e em relação a eles próprios. Em relação às mulheres e crianças, há uma tendência à glorificação da violência, sexismo, misoginia, objetificação sexual e concepções rígidas de gênero que parecem criar uma heteronormatividade como imperativa na socialização masculina. 
Outro fator de risco componente desta tríade, diz respeito aos comportamentos dos homens aos outros homens, incluindo acidentes, homicídios e transmissão de HIV/AIDS. O último fator da tríade de risco mencionado pelo estudo da OPS/OMS (2019), compreende a relação dos homens a si mesmos, fatores como autossuficiência, competitividade, individualismo, suicídios, acidentes, adicção e doenças psicossomáticas intrincados na subjetivação, articulam uma socialização masculina que afeta a saúde dos homens.

Alguns dados sobre a persistência, e até mesmo o aumento da violência contra as mulheres no Brasil, bem como dados sobre a índices de suicídio masculinos podem auxiliar a dimensionar o problema. De acordo com o Atlas da Violência de 2019, houve um crescimento expressivo de 30,7\% no número de homicídios de mulheres no país, durante o período de 2007 a 2017. O Atlas (2019) distingue ainda, o aumento da violência de forma expressiva na população de mulheres negras. Citam: "Enquanto a taxa de homicídios de mulheres não negras teve crescimento de 4,5\% entre 2007 e 2017, a taxa de homicídios de mulheres negras cresceu 29,9\%" (FÓRUM BRASILEIRO DE SEGURANÇA PÚBLICA - FBSP, 2019, p.38).

A maioria dos crimes letais cometidos contra mulheres, de acordo com a literatura internacional, ocorrem dentro das residências e são perpetrados por conhecidos ou pessoas íntimas das vítimas (Instituto de Pesquisa Econômica Aplicada - IPEA; Fórum Brasileiro de Segurança Pública - FBSP, 2019). Essas informações possibilitam o questionamento: em que medida as concepções de masculinidade formadas por crenças, relativas aos ideais de força e de agressividade, teriam conexão com tais violências?

Com as medidas de isolamento social adotadas em relação à pandemia da Covid19 , os riscos à vida das mulheres têm aumentado, acarretando uma série de consequências para as situações de violências contra as mulheres no Brasil e no mundo. Segundo o Fórum Brasileiro de Segurança Pública (2020, p.15): 
[...] os números de feminicídios e homicídios femininos apresentam crescimento, indicando que a violência doméstica e familiar está em ascensão. Em São Paulo o aumento dos feminicídios chegou a 46\% na comparação de março de 2020 com março de 2019 e duplicou na primeira quinzena de abril (FBSP, 2020, p. 15).

Em relação ao terceiro eixo dos fatores de risco, dos homens em relação a si próprios, indicativos de mortalidade apresentados pela OPS/OMS (2019) constatam que os homens tendem a morrer 718,8/100.000 em comparação a 615,1/100.000 mulheres. O documento ainda associa as causas das mortes, bem como os fatores de risco, como reflexos de uma conduta esperada pela masculinidade hegemônica com expressões tóxicas.

Dados atualizados do Sistema de Informações de Mortalidade do Sistema Único de Saúde (SIM/SUS, 2018), evidenciam que no período de 2018, no estado de São Paulo, a taxa de mortalidade de homens com idade entre 20 a 29 anos é de 852 casos, sendo a ocorrência da morte por agressão. O Datasus (2018, n.p) inclui como agressão: "homicídio, lesões infligidas por outra pessoa, empregando qualquer meio, com a intenção de lesar (ferir) ou de matar". Para as mulheres a taxa de mortalidade na categoria de agressão no período de 2018, estado de São Paulo, com idade entre 20 e 29 anos, é de 96 casos.

Em relação às tentativas de suicídio (lesões autoprovocadas voluntariamente), 0 SIM/SUS apresenta um total de 357 casos no estado de São Paulo de homens com idade entre 20 e 29 anos, no ano de 2018. Em relação às mulheres, após a aplicação dos mesmos filtros no Sistema de Informações de Mortalidade, a taxa é de 100 casos.

Dessa forma, o interesse sobre o tema da constituição das subjetividades masculinas é, portanto, extremamente pertinente, visto que a socialização da masculinidade na contemporaneidade inclui a possibilidade de comportamentos prejudiciais aos homens em relação a si mesmos, aos outros homens, às mulheres e crianças, ou seja, a sociedade como um todo. 
Com base nas problemáticas supramencionadas, considera-se relevante investigar a literatura recente da abordagem psicanalítica, produzida no Brasil, que vinculam masculinidade e psicanálise, por meio de uma revisão sistemática descritivaexploratória de apresentação dos dados qualitativa, para compreender de que maneira a psicanálise aborda a questão da masculinidade nas pesquisas recentes publicadas no Brasil.

\section{MASCULINIDADES E FEMINILIDADES PARA A PSICANÁLISE}

Masculinidade e feminilidade, no âmbito da psicanálise, não são definições naturalizadas decorrentes do aparato biológico. Do pondo de vista psicanalítico, a construção de gênero perpassa lugares simbólicos e imaginários que se estruturam no processo de subjetivação a partir das trocas intersubjetivas.

Freud (2011, p. 268) argumenta que, "masculinidade e feminilidade puras permanecem sendo construções teóricas de conteúdo incerto", o psicanalista aprofunda o argumento na conferência XXII (1932 - 1936) sobre a feminilidade. Coelho (2013) ressalta que na conferência, Freud tece uma crítica sobre a definição da diferença sexual, à medida que se estabelecem padrões de comportamentos para ambos os sexos.

Desta forma, Freud (2010, p.265 - 266) inicia o texto com o seguinte questionamento:

Ao deparar com um outro ser humano, a primeira distinção que fazem é "macho ou fêmea", e estão habituados a fazer essa distinção com tranquila certeza. [...] Vocês são convidados a familiarizar-se com a ideia de que a proporção em que masculino e feminino se misturam, no ser individual, está sujeita a consideráveis variações. Mas como, excetuando casos raríssimos, apenas um tipo de produto sexual - óvulos ou sêmen - se acha presente numa pessoa, vocês devem ter dúvidas quanto ao significado decisivo desses elementos e concluir que o que constitui a masculinidade ou feminilidade é uma característica desconhecida, que a anatomia não pode apreender. 
Portanto, para a psicanálise, masculinidade e feminilidade não correspondem ao aparato anatômico, e, caso sejam atribuídos comportamentos "ativo - masculino" e "passivo - feminino" não existe um propósito para análise que seja útil. A construção de gênero, portanto, é de via simbólica e imaginária, estruturadas nos processos de subjetivação. Segundo Cossi e Dunker (2017), para Freud, é por meio do Complexo de Édipo que os sujeitos de definem como homem ou mulher, visto que o desfecho é a formação da identidade de gênero.

Para discutir a concepção de masculinidade pela via da psicanálise, utilizaremos algumas distinções realizadas por Laplanche (2015) o qual explicita o funcionamento primordial do ser humano na história da tríade gênero, sexo e o sexual. Segundo o autor, "o Sexual, para Freud, é, pois, exterior ou mesmo anterior à diferença dos sexos, para não dizer, à diferença dos gêneros; ele é oral, anal ou paragenital." (LAPLANCHE, 2015, p.157). Define ainda o termo Sexual como: "o Sexual poderia ser definido como "o que é condenado pelo adulto" (LAPLANCHE, 2015, p.158) e, portanto, recalcado por ser Sexual. Laplanche aponta a dificuldade de se definir o Sexual de forma ampliada, visto que parece se sustentar na sexualidade dita clássica. Desta forma, introduz um outro termo: gênero.

O autor realiza uma retomada histórica sobre o conceito, o qual foi fortemente difundido por sociólogos e pela literatura feminista. Cabe ressaltar que o conceito de gênero foi introduzido inicialmente pelo sexólogo J. Monet, em 1955, sendo retomado pelo psicanalista R. Stoller, que, em 1968, cunhou o termo "identidade nuclear de gênero" ou "núcleo da identidade de gênero" (LAPLANCHE, 2015).

Para Laplanche (2015) o que ocorre é uma "guerra" de conceitos e termos, ou seja, o gênero contra o sexo e quando gênero e sexo estão aliados, contra o sexual. $O$ que isso quer dizer? Laplanche exemplifica nomeando um duplo movimento existente na maior parte da literatura feminista:

Há um primeiro movimento de subversão da noção de sexo, chegando a anulá-lo numa pura retroação pelo gênero; e depois, um 
momento em que se percebe a necessidade, apesar de tudo, de conceber algo na base, ainda que seja justamente para subvertê-lo e anulá-lo: uma espécie de natureza pura ou, como diz Beauvoir, "fatos que não têm sentido em si mesmos. (LAPLANCHE, 2015, p. 160).

Dessa forma, observa-se um movimento que procura a "desnaturalização" da natureza, e neste movimento a referência feita à psicanálise têm o sexual totalmente ausente. A psicanálise é referida como uma teoria que subordina o gênero ao sexo. Entretanto, Laplanche (2015) argumenta que apesar da palavra gênero não aparecer nos escritos de Freud, justamente pela língua alemã não permitir, visto que Geschlecht significar sexo e gênero ao mesmo tempo, o conceito aparece de outras formas. Assim, o autor introduz os três pares de oposição no ser humano: ativopassivo, fálico-castrado e feminino - masculino.

Nos reteremos ao terceiro par de oposição, o feminino e o masculino. Freud (19311936, citado por LAPLANCHE, 2015, p. 168) explica que "masculino e feminino constituem a primeira diferenciação que fazemos quando encontramos outro ser humano, e somos acostumados a fazê-la com uma certeza isenta de dúvida". A diferenciação, portanto, não é realizada segundo os órgãos genitais, mas sim, segundo Laplanche (2015) são os habitus de ambos os sexos que caracterizam a diferença. Neste sentido, "é a criança na presença do adulto que se interroga sobre essa diferença presente no adulto" (LAPLANCHE, 2015, p. 169).

Assim, para definir gênero o autor se utiliza do termo designação, o que corresponde ao primado do outro. Designação é "um conjunto de atos que se prolongam na linguagem e nos comportamentos significativos do entorno [...] uma designação contínua ou de uma verdadeira prescrição" (LAPLANCHE, 2015, p.171). Podemos compreender como designação este conjunto de atos que vão sendo acatados ao longa da história dos sujeitos, e ela ocorre no núcleo familiar que se insere no social, o que Laplanche (2015) denomina "socci próximos".

Esse conjunto de atitudes, crenças e valores que vão orientar o sujeito são conquistados por meio do processo de identificação. Laplanche e Pontalis (2001) 
definem identificação como "processo psicológico pelo qual um sujeito assimila um aspecto, uma propriedade, um atributo do outro e se transforma, total ou parcialmente, segundo o modelo desse outro. A personalidade constitui-se e diferencia-se por uma série de identificações." (LAPLANCHE e PONTALIS, 2001, p. 226). Neste sentido, percebe-se a identificação como um mecanismo no qual os sujeitos vão se constituindo tanto como masculinos, femininos ou outras designações de gênero, a partir do outro, na cultura. Linguagens, cuidados corporais, os códigos sociais, passam então a ser mensagens de designação do gênero, na qual os sujeitos se identificam por meio destes ruídos inconscientes que envolvem a compreensão e performance de gênero.

Tendo em vista os processos identificatórios descritos pela psicanálise, pode-se definir masculinidade como:

[...] lugar simbólico/imaginário de sentido estruturante nos processos de subjetivação [...] na qualidade de estrato constitutivo e articulado no socius, apresenta-se como uma significação social, um ideal culturalmente elaborado ou sistema relacional que aponta para uma ordem de comportamentos socialmente sancionados". (OLIVEIRA, 2004, p.13).

À medida que essa "ordem de comportamentos socialmente sancionados", articula os sujeitos à uma masculinidade associada a conceitos como "virilidade, força, coragem, capacidade de combate, o "direito" à violência e aos privilégios associados a dominação" (MOLINIER; WELZER-LANG, 2009, p. 101), faz-se necessário elucidar como se dão estes processos de subjetivação, resultando assim em uma desnaturalização de características imperativas associadas aos sexos.

A fim de avançar sobre os questionamentos não somente sobre a constituição da subjetividade masculina, o psicanalista Joel Birman (2018) ressalta que tem ocorrido importantes transformações em torno da sexualidade que pressupõe a legitimação da "existência de práticas sexuais no plural, e não no singular, o que implica o reconhecimento e o rompimento com os padrões sexuais anteriormente existentes na tradição ocidental" (BIRMAN, 2018, p.138). Para o autor, um dos alicerces que 
constituíam o campo da sexualidade no Ocidente e que foram radicalmente transformados, foi o patriarcado, "uma vez que era a tradição patriarcal o que caucionava a relação hierárquica existente entre as figuras do homem e da mulher" (BIRMAN, 2018, p. 139). A heterossexualidade compulsória passa a ser questionada, dando visibilidade aos discursos homossexuais, bissexuais e transexuais.

Segundo Birman:

[...] foi a desconstrução progressiva da relação hierárquica entre os gêneros, assim como a colocação em questão da heterossexualidade compulsória o que transformou e subverteu as coordenadas instituídas no campo da sexualidade, de forma que foram essas as condições concretas de possibilidade para a constituição de outro campo sexual no Ocidente (BIRMAN, 2018, p.139).

Neste sentido, após breve exposição de uma das perspectivas teóricas da psicanálise sobre o tema, questiona-se as problemáticas vinculadas à masculinidade que são abordadas em literatura dos último dez anos, publicada no Brasil. Os conflitos apresentados brevemente entre a psicanálise e os estudos de gênero estão presentes? De que forma? Como a psicanálise vem se inserindo neste contexto complexo?

\section{ASPECTOS METODOLÓGICOS}

Trata-se de uma pesquisa de revisão bibliográfica sistemática do tipo descritivaexploratória, ou seja, que busca descrever as características de fenômeno específicos, bem como, identificar os fatores que determinam ou que contribuem para a ocorrência do fenômeno a ser estudado a partir do levantamento e seleção de toda bibliografia já publicada acerca do assunto proposto (GIL, 2007).

O âmbito da pesquisa bibliográfica sistematizada ocorreu na base "Portal de Periódicos da Coordenação de Aperfeiçoamento de Pessoal de Nível Superior (Capes)" - biblioteca virtual criada pelo Ministério da Educação (MEC)" entre 
setembro a dezembro do ano de 2020. O portal tem com o objetivo de fortalecer a pós-graduação no Brasil, por meio do Google Acadêmico e da Biblioteca Eletrônica Científica Online Scielo.

Os descritores para seleção dos artigos foram: "masculinidade" and "psicanálise" no campo de busca avançada "assunto", além disso, neste campo de busca avançada, foram incluídos os itens que a própria plataforma disponibiliza, como "data de publicação: qualquer ano", "tipo de material: todos os itens" e "idioma: qualquer idioma".

Foram consideradas apenas produções que contemplavam o tema "masculinidade" em conjunto com a perspectiva teórica da psicanálise, sob a ótica da análise por esta via, ou pela crítica; periódicos revisados por pares; data da publicação nos últimos 10 anos, e todos os idiomas disponíveis.

Como critério de exclusão, foram eliminados: estudos que não contemplem os temas "masculinidade" e "psicanálise"; periódicos não revisados por pares; data da publicação superior há 10 anos.

Quadro 1 - Etapas do processo de revisão sistemática da literatura

\begin{tabular}{|c|c|}
\hline Dbjetivos & $\begin{array}{l}\text { Identificar estudos que: a) abrangem discussões sobre } \\
\text { masculinidade pela perspectiva teórica da psicanálise; b) } \\
\text { abrangem discussões sobre masculinidades pela } \\
\text { perspectiva teórica de autores que realizam críticas à } \\
\text { psicanálise. }\end{array}$ \\
\hline $\begin{array}{l}\text { Equações } \\
\text { pesquisa }\end{array}$ & Expressão Masculinidade "and" Psicanálise. \\
\hline $\begin{array}{l}\text { Âmbito } \\
\text { pesquisa }\end{array}$ & Portal de Periódicos CAPES/MEC. \\
\hline térios & tigos que contemplem \\
\hline
\end{tabular}




\begin{tabular}{|c|c|}
\hline inclusão & $\begin{array}{l}\text { com a perspectiva teórica da psicanálise, sob a ótica da análise } \\
\text { por esta via, ou pela crítica; periódicos revisados por pares; } \\
\text { publicados nos últimos } 10 \text { anos; idioma português. }\end{array}$ \\
\hline $\begin{array}{l}\text { Critérios } \\
\text { exclusão }\end{array}$ & $\begin{array}{l}\text { Estudos que não contemplem os temas "masculinidade" e } \\
\text { "psicanálise"; periódicos não revisados por pares; data da } \\
\text { publicação anterior há } 10 \text { anos. }\end{array}$ \\
\hline $\begin{array}{l}\text { Critérios de } \\
\text { validade } \\
\text { metodológica }\end{array}$ & $\begin{array}{l}\text { Verificação dos critérios de inclusão e exclusão e artigos } \\
\text { revisados por pares. }\end{array}$ \\
\hline Resultados & $\begin{array}{l}\text { Registro de todos os estudos apresentados pela plataforma } \\
\text { "Portal de Periódicos CAPS/MEC", após a aplicação dos filtros; } \\
\text { leitura dos resumos para a seleção dos estudos sob os critérios } \\
\text { de inclusão e exclusão. }\end{array}$ \\
\hline $\begin{array}{l}\text { Tratamento dos } \\
\text { dados }\end{array}$ & o os estudos encontrados. \\
\hline
\end{tabular}

Fonte: Adaptado de RAMOS; FARIA; FARIA (2014, p. 24).

O quadro 1 apresenta as etapas do processo de revisão sistemática da literatura, após a definição dos objetivos da busca de estudos que tem como tema "masculinidade e psicanálise", tendo em vista os critérios de inclusão e exclusão mencionados. Em resposta a esses critérios, a plataforma apresentou o total de 62 trabalhos, dentre eles, artigos e resenhas de livros.

É importante ressaltar que a plataforma disponibiliza filtros como "tipo de recurso" 'tópico", "autor", "data de publicação", "coleção", "idioma” e "título do periódico" que podem ser selecionados durante a pesquisa, a soma total de artigos incluindo estes filtros corresponde a 743 artigos. O número de 62 trabalhos passa pelo crivo dos "artigos revisados por pares", "data de publicação" e "idiomas". O quadro a seguir demonstra estes resultados. 
Quadro 2 - Resultados personalizados do Portal de Periódicos da Coordenação de Aperfeiçoamento de Pessoal de Nível Superior (Capes).

\begin{tabular}{|c|c|c|}
\hline \multicolumn{2}{|l|}{ Resultados } & Total \\
\hline \multicolumn{2}{|c|}{ Periódicos revisados por pares } & 62 \\
\hline \multirow[t]{2}{*}{ Tipo de recurso } & Artigos & 61 \\
\hline & Resenhas & 1 \\
\hline \multirow[t]{20}{*}{ Tópico } & Women'S Studies & 29 \\
\hline & Psychology, Multidisciplinary & 18 \\
\hline & Gender & 15 \\
\hline & Gênero & 10 \\
\hline & Psychoanalysis & 9 \\
\hline & Brazil & 9 \\
\hline & Sexuality & 8 \\
\hline & Women & 7 \\
\hline & Psicanálise & 7 \\
\hline & Law & 6 \\
\hline & Feminism & 6 \\
\hline & Politics & 6 \\
\hline & Psychology & 5 \\
\hline & Femininity & 5 \\
\hline & Queer Theory & 4 \\
\hline & Sociology \& Social History & 4 \\
\hline & Masculinidade & 4 \\
\hline & Masculinity & 4 \\
\hline & Business & 3 \\
\hline & Transsexuality & 3 \\
\hline \multirow[t]{3}{*}{ Autor } & Anselmo Peres Alós & 3 \\
\hline & Diniz, Ana Paula Rodrigues & 2 \\
\hline & Bento, Berenice & 2 \\
\hline
\end{tabular}

RC: 85791

Disponível

em: https://www.nucleodoconhecimento.com.br/psicologia/masculinidades-epsicanalise 


\begin{tabular}{|c|c|c|}
\hline & Grossi, Miriam Pillar & 2 \\
\hline & Pontes, Heloisa & 2 \\
\hline & Alós, Anselmo Peres & 2 \\
\hline & Passos, Lara & 1 \\
\hline & Ferreira, Vinicius Kauê & 1 \\
\hline & Mara Coelho de Souza Lago & 1 \\
\hline & Wittmann, Isabel & 1 \\
\hline & Ribeiro, Loredana & 1 \\
\hline & Schimidt, Sarah & 1 \\
\hline & Muzzio, Henrique & 1 \\
\hline & Tatagiba, Ana Paula & 1 \\
\hline & Miceli, Sergio & 1 \\
\hline & Signorelli, Marcos Claudio & 1 \\
\hline & Oliveira, Daniel Canavese & 1 \\
\hline & Aguiar, Ana Rosa Camill & 1 \\
\hline & Popadiuk, Gianna Schreiber & 1 \\
\hline & Cardoso, Cláudia Pons & 1 \\
\hline Data de publicação & De 2010 a 2020 & 62 \\
\hline Coleção & OneFile (GALE) & 44 \\
\hline & Directory of Open Access Journals (DOAJ) & 39 \\
\hline & SciELO (CrossRef) & 29 \\
\hline & Sociological Abstracts & 32 \\
\hline & SciELO Brazil & 6 \\
\hline & Scopus (Elsevier) & 23 \\
\hline & Materials Science \& Engineering Database & 2 \\
\hline & ScieELO Public Health & 1 \\
\hline & JSTOR Archival Journals & 16 \\
\hline Idioma & Português & 50 \\
\hline & Inglês & 53 \\
\hline
\end{tabular}




\begin{tabular}{|l|l|l|}
\hline \multirow{3}{*}{ Título do periódico } & Espanhol & 27 \\
\hline & Cadernos EBAPE.BR & 2 \\
\hline & Ciência \& Saúde Coletiva & 1 \\
\hline & Direito e Praxis & 4 \\
\hline & Estudos feministas & 28 \\
\hline & Latin American Research Review & 1 \\
\hline & Opinião Pública & 1 \\
\hline & Psicologia e Saber Social & 1 \\
\hline Psicologia em Revista & 1 \\
\hline Psicologia USP & 1 \\
\hline & Psicologia: Teoria e Pesquisa & 2 \\
\hline Revista Artemis & 7 \\
\hline Revista Ártemis & 3 \\
\hline Revista de Gestão e Secretariado & 1 \\
\hline Revista Direito e Práxis & 4 \\
\hline Revista Estudo Feministas & 20 \\
\hline Revista Estudos Feministas & 25 \\
\hline Sociologia \& Antropologia & 1 \\
\hline Tempo Social & 1 \\
\hline
\end{tabular}

Fonte: quadro elaborada pelas autoras.

O quadro 2 apresenta, portanto, os resultados da primeira etapa de seleção nos dados do Portal de Periódicos da Capes. Inicialmente, são apresentadas as publicações que se encaixam nos critérios de inclusão estabelecidos, ou seja, 61 artigos e 1 resenha de livro. Após esta primeira busca, foram realizados refinamentos dos resultados com os seguintes filtros: artigos publicados com revisão entre pares, data da publicação nos últimos 10 anos, em idioma português.

A seleção dos estudos ocorreu em duas (2) fases, em um primeiro momento, foi realizada a leitura dos resumos dos 62 estudos. A seleção ou exclusão destes 
trabalhos ocorreu por meio do específico critério de inclusão: estudos que contemplem o tema "masculinidades" em conjunto com a perspectiva teórica da psicanálise, sob a ótica da análise por esta via, ou pela crítica. Como resultado da primeira etapa, foram selecionados inicialmente 32 publicações, os assuntos presentes nos artigos englobavam estudos sobre feminismo, filosofia, teoria social, sexualidade, gênero, despatologização, teoria queer, violência de gênero e racismo.

Após a seleção dos 32 estudos, foi realizada a segunda etapa, uma leitura aprofundada de cada uma destas publicações. Neste sentido, foi possível efetuar uma nova filtragem, na qual foram retirados os artigos que não contemplavam o tema das masculinidades como foco central. O tópico seguinte apresenta a seleção final dos artigos, aos quais serão discutidos nesta revisão sistemática.

\section{DISCUSSÃO E RESULTADOS}

Previamente à apresentação dos resultados da revisão sistemática, consideramos importante apresentar os resultados apresentados pelo Portal da Biblioteca Digital de Teses e Dissertações da Universidade de São Paulo que verificam um crescimento nos estudos sobre masculinidades, com um total de 54,855 dissertações de mestrado entre os anos de 1968 e 2020. Já em relação às teses de doutorado, temos o número de 38,320 estudos entre os anos de 1942 e 2020. Desta forma, no âmbito do mestrado a plataforma indica um interesse maior sobre o assunto neste nível de pós-graduação. Quando pesquisado o termo "masculinidade e psicanálise" na plataforma de teses e dissertações, não foram encontrados resultados para a busca, os resultados obtidos se restringem apenas ao termo "masculinidade". A figura a seguir apresenta as informações obtidas na pesquisa: 
Figura 1 - Gráfico de Dissertações de mestrado disponíveis sobre o tema masculinidade na Biblioteca Digital de Teses e Dissertações da USP.

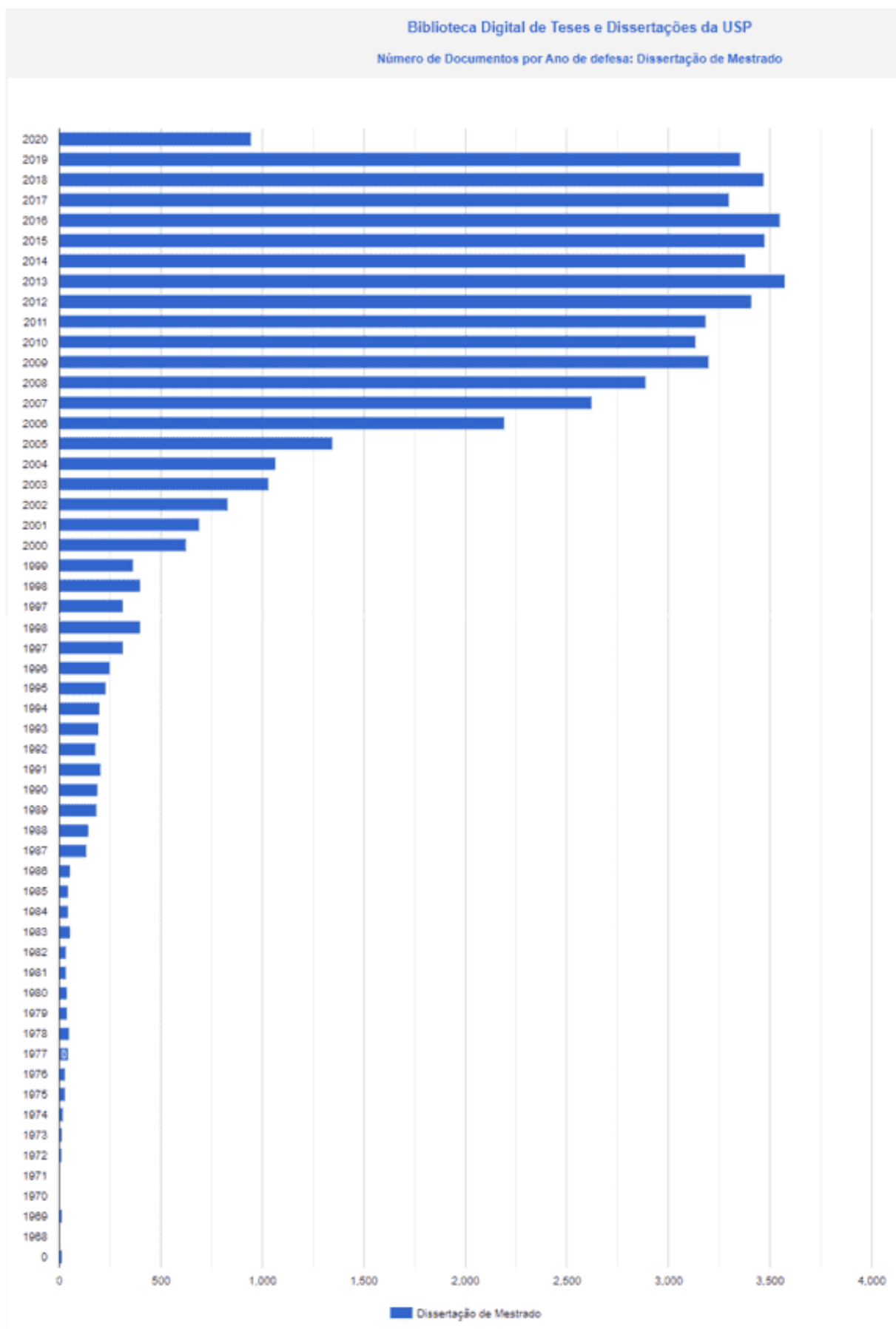

Fonte: Biblioteca Digital de Teses e Dissertações da Universidade de São Paulo USP.

RC: 85791

Disponível

em: https://www.nucleodoconhecimento.com.br/psicologia/masculinidades-epsicanalise 
Os últimos 10 anos de pesquisa parecem ter sido os mais ocorrentes no que diz respeito às produções cientificas sobre o tema. Percebe-se, portanto, o interesse crescente de discussões sobre masculinidade, possivelmente influenciadas pelo movimento feminista do final da década de 60 , bem como a visibilidade do movimento $\mathrm{LBGTQI}_{+}$, visto que podem ser caracterizados como fatores que implicam novas significações para a instituição de novas formas de subjetivação dos sujeitos.

Como resultado da revisão sistemática à que pretende este artigo, inicialmente obteve-se: sessenta e dois (62) trabalhos disponíveis no Portal de Periódicos da Coordenação de Aperfeiçoamento de Pessoal de Nível Superior (Capes). A partir da leitura dos resumos e posteriormente artigos na integra, foi possível selecionar trinta e dois (32) trabalhos por meio dos critérios de inclusão e exclusão já mencionados. As publicações se concentram em trinta e um (31) artigos e uma (1) resenha de livro, os artigos e a resenha foram publicados nos seguintes periódicos: Cadernos EBAPE.BR, Ciência \& Saúde Coletiva, Direito e Práxis Revista de Estudos feministas, Latin American Research Review, Opinião Pública, Psicologia e Saber Social, Psicologia em Revista, Psicologia USP, Psicologia: Teoria e Pesquisa, Revista Artemis, Revista Ártemis, Sociologia \& Antropologia e Revista Tempo Social.

Em relação às datas de publicação o ano de maior incidência foi de 2016 com sete (7) publicações, seguidas de: 2014 com quatro (4), 2010 também com quatro (4) estudos publicados. Os anos de 2013, 2012, 2019 e 2010, possuem três (3) pesquisas, já os anos de 2011 e 2018 demonstram dois (2) trabalhos, sendo 2015 o ano com menos publicações, uma (1). 
Gráfico 1 - Ano de publicações.

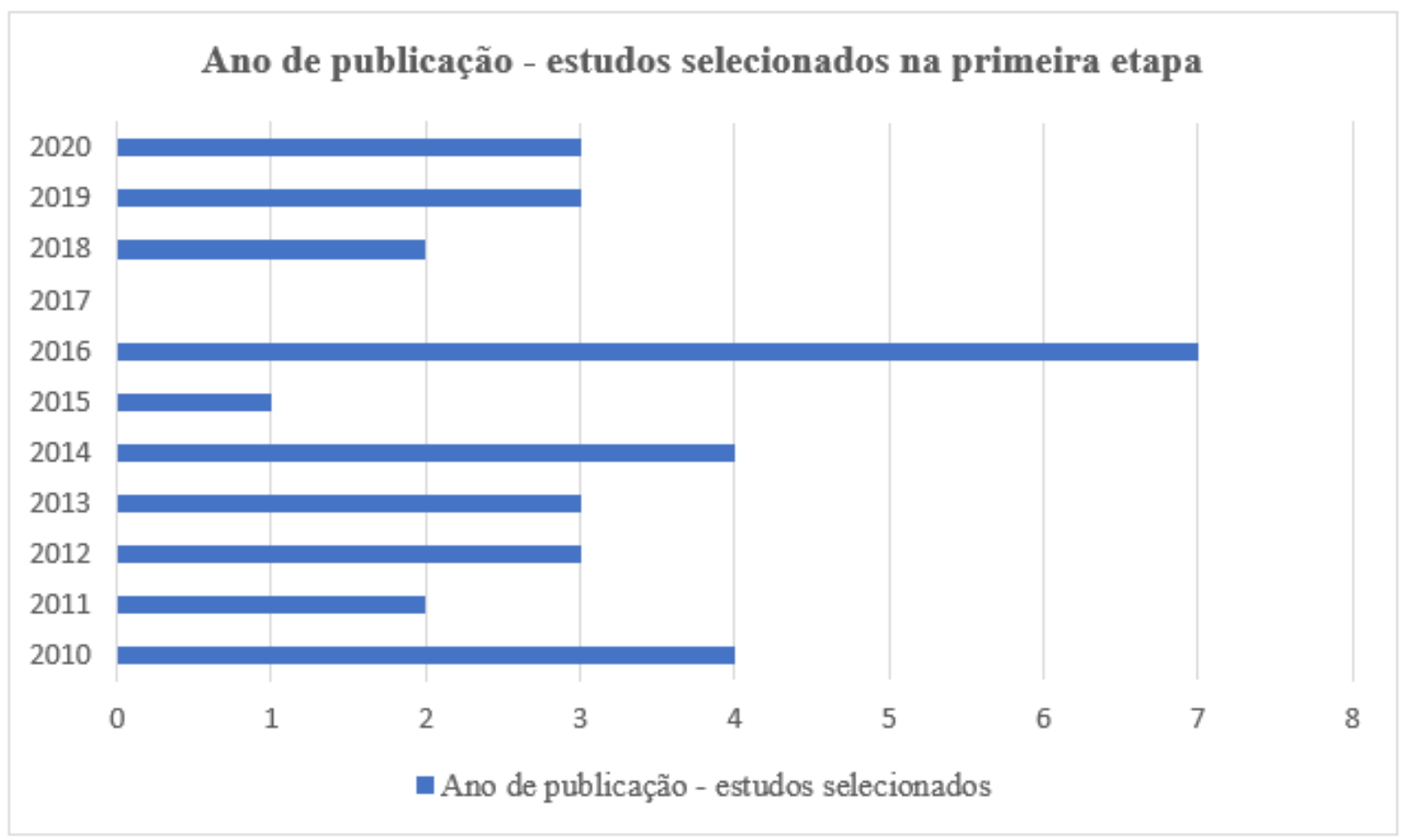

Fonte: gráfico elaborado pelas autoras.

$\mathrm{Na}$ segunda etapa, após a leitura dos artigos na integra, foi possível selecionar o total de três (3) estudos que obtinham como perspectiva central a discussão do tema masculinidade e psicanálise. O quadro a seguir apresenta o resultado final na seleção dos estudos:

Quadro 3 - Seleção final dos artigos após a leitura na integra.

\section{№ ESTUDOS} SELECIONADOS

1 Título: A escuta do "Este estudo tem o objetivo de compreender as masculino na clínica configurações de padecimento psíquico psicanalítica contemporânea: singularidades

\section{OBJETIVOS} masculino que se fazem presentes na clínica psicanalítica contemporânea. Para tal, buscou-se de um entrevistar psicanalistas os quais, a partir da

RC: 85791

Disponível

em: https://www.nucleodoconhecimento.com.br/psicologia/masculinidades-epsicanalise 
padecer.

Autor: Fernanda Cesa

Ferreira da Silva; Monica

Medeiros Kother Macedo.

Idioma: português

Publicado em: Psicologia:

Teoria e Pesquisa, AprilJune, 2012, Vol.28(2), p.205(13).

2 Título: A feminilidade como uma posição de sujeito: uma abordagem lacaniana

Autor: Bruno Alves Coelho

Idioma: português

Publicado em: Psicologia USP, São Paulo, 2013, 24(1), 99-117.

\section{Título: Masculinidade} hegemônica: repensando o conceito. escuta de demandas e padecimentos masculinos, permitissem realizar reflexões a respeito desta especificidade de prática clínica com homens".

"O objetivo do presente trabalho é diferenciar duas formas de pensar a feminilidade. A primeira, entendida a partir da economia libidinal de um homem e a segunda como uma forma própria de um sujeito se constituir sexuado. Neste trabalho, a feminilidade é pensada como uma posição do sujeito, e buscamos aproximar alguns dos principais conceitos que Freud e Lacan usam para pensar a feminilidade, nomeadamente, no caso de Freud, no que diz respeito à configuração particular da libido feminina entre a libido objetal e a libido narcísica e, no caso de Lacan, no que diz respeito à relação da mulher com o falo ser mediada por uma forma diferente de relação com o Outro".

"O conceito de masculinidade hegemônica tem influenciado os estudos de gênero em vários campos acadêmicos, mas ao mesmo tempo tem atraído um sério criticismo. Os autores traçam a 
Autor: Robert W. Connell e origem do conceito a uma convergência de ideias James W. Messerschmidt no início dos anos 1980 e mapeiam as formas

Idioma: português através das quais o conceito foi aplicado quando

Publicado em: Gender \& os estudos sobre homens e masculinidades se Society, v. 19, n. 6, p. 829 expandiram. Avaliando as principais críticas, os autores defendem o conceito de masculinidade 859, Dec. 2005 como fundamental, uma vez que, na maioria das pesquisas que o opera, seu uso não é reificador nem essencialista".

Fonte: quadro elaborado pelas autoras.

Foi possível, portanto, identificar que os estudos de forma geral, contemplam a questão da masculinidade e da psicanálise, entretanto, aprofundaremos três questões que se sobressaíram durante a análise. Os resultados foram organizados de acordo com três eixos temáticos. O quadro a seguir permite a visualização desses eixos:

Quadro 4 - Eixos temáticos

1 Estudos psicanalíticos no Estudos em que a psicanálise aparece como foco âmbito das central na discussão da masculinidade. A teoria é masculinidades utilizada como recurso de leitura para a constituição da masculinidade.

2 Estudos de gênero com Os estudos nesse eixo temático objetivam discutir foco ampliado gênero de forma ampliada, incluindo debates sobre identidade de gênero, mas que não se aprofundam na especificidade das masculinidades.

3 Estudos de gênero que Nesse eixo temático, os estudos de gênero contemplam

a contemplam as questões das masculinidades e se psicanálise de forma utilizam do discurso psicanalítico de forma 
interdisciplinar interdisciplinar, à medida que a teoria é referida como uma referência de articulação com os estudos de gênero ou mesmo crítica.

Fonte: quadro elaborada pelas autoras

O eixo 1 "Estudos psicanalíticos no âmbito das masculinidades", indica trabalhos escassos sobre o tema de acordo com a pesquisa realizada no Portal de Periódicos da Coordenação de Aperfeiçoamento de Pessoal de Nível Superior (Capes). Do total de 62 estudos, apenas 2 deles contemplam o tema masculinidade pela via psicanalítica. São estes: "a escuta do masculino na clínica psicanalítica contemporânea: singularidades de um padecer" e "a feminilidade como uma posição de sujeito: uma abordagem lacaniana".

Os estudos têm como foco central a leitura pela via psicanalítica dos fenômenos relacionados a masculinidades e tem como um dos conceitos centrais a subjetividade. Propõe-se a pensar os momentos iniciais do desenvolvimento e sua importância para a constituição da subjetividade dos sujeitos, delimitando a constituição subjetiva ao contexto da contemporaneidade e correlacionando com um suposto mal-estar existente em virtude de transformações ocorridas no campo sexual, como as citadas anteriormente por Birman (2018), em relação aos questionamentos à heterossexualidade compulsória.

O quadro a seguir, demonstra os autores psicanalíticos mais utilizados, de acordo com autores clássicos aos mais recentes.

Quadro 5 - Autores psicanalíticos citados nos artigos enquadrados no eixo 1.

Artigos

1 A escuta do masculino na clínica psicanalítica Sigmund Freud contemporânea: singularidades de um 


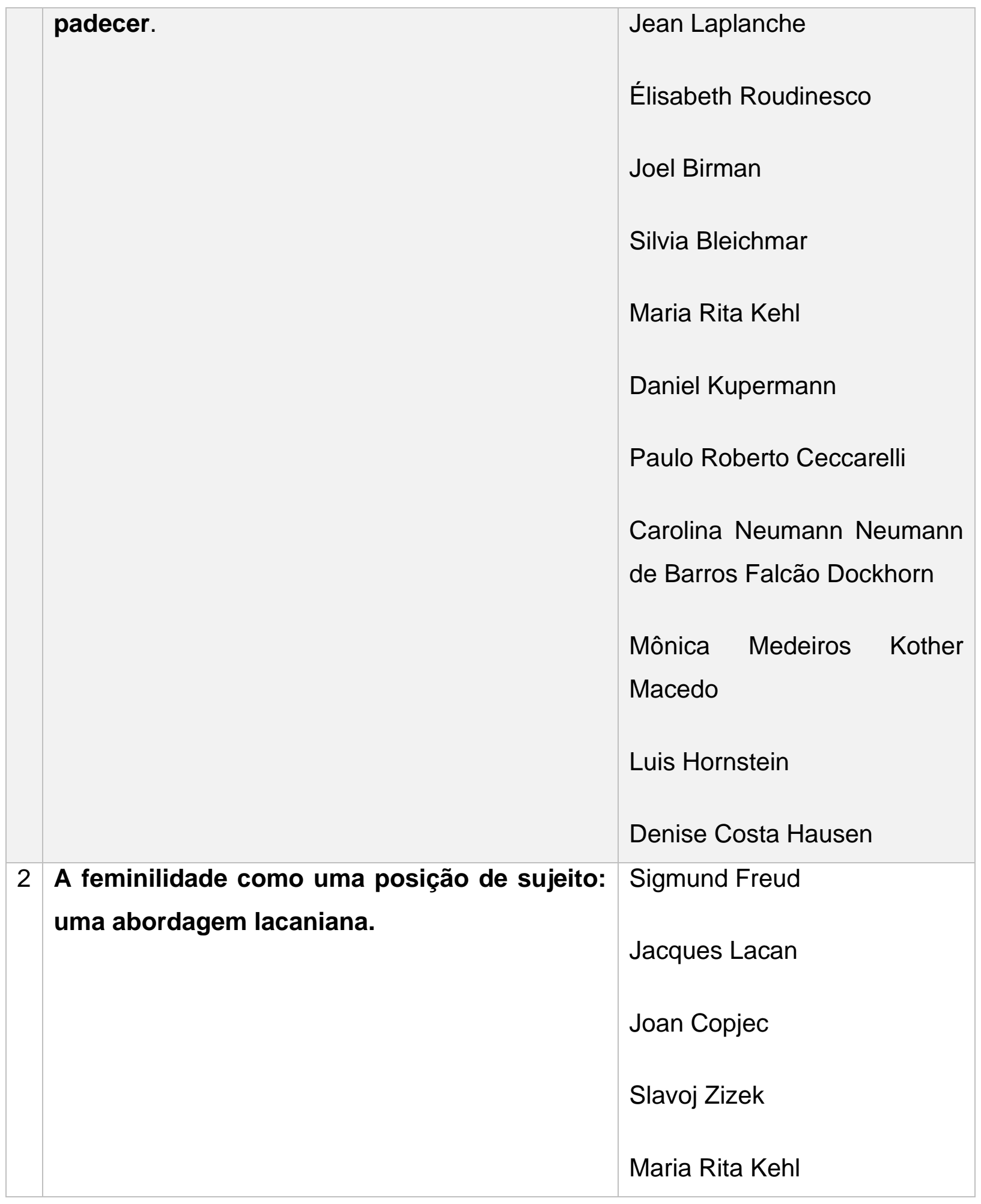

Fonte: quadro elaborada pelas autoras. 
Os autores comuns aos artigos são Sigmund Freud (1856 - 1939) e Maria Rita Kehl (1951). Os textos citados dos referidos autores referem-se a:

Quadro 6 - Textos referenciados nos artigos - eixo 1.

\begin{tabular}{|c|c|}
\hline $\begin{array}{l}\text { Sigmund Freud (1856 } \\
\text { - 1939) }\end{array}$ & $\begin{array}{l}\text { Contribuições à psicologia do amor I e II (1910). } \\
\text { Sexualidade feminina (1931). } \\
\text { Esboço de psicanálise (1938). } \\
\text { O ego e o id (1923). } \\
\text { anatômica entre os sexos (1925). } \\
\text { Conferência XXXIII: feminilidade (1933). } \\
\text { Três ensaios sobre a teoria da sexualidade (1905). } \\
\text { Sobre o narcisismo: uma introdução (1914). } \\
\text { Análise de uma fobia em um menino de } \\
\text { cinco anos (1909). } \\
\text { À guisa de introdução ao narcisismo (1914). } \\
\text { Conferência XXVII: Transferência (1914). }\end{array}$ \\
\hline
\end{tabular}


Maria Rita Kehl . Deslocamentos do feminino (2008).

A mínima diferença: Masculino e feminino na cultura (1996).

A impostura do macho (2004).

Fonte: quadro elaborada pelas autoras.

Percebe-se, o autor Freud, como uma referência clássica por fundar a psicanálise, e ainda pelo foco central no desenvolvimento humano via sexualidade. As discussões sobre a diferença sexual parecem ser o ponto de partida a que se referem os artigos para discutir masculinidades. O autor ainda é muito citado pela possibilidade de recurso de leitura dos processos de subjetivações e dinâmicas dos sujeitos. É interessante notar que, a psicanálise no interim da própria teoria possui diferentes interpretações dos fenômenos subjetivos e culturais. Entretanto, a escola Francesa aparece como uma referência. Além de Freud, um autor bastante citado é Jacques Lacan, devido as vastas contribuições para a teoria freudiana.

Outra questão presente nos estudos que adotam a psicanálise como ferramenta de leitura da realidade, é a importância da dinâmica edípica para o processo de identificação. Estes dois conceitos aparecem de forma bastante frequente: Complexo de Édipo e identificação. É importante ressaltar ainda os estudos retomam a ideia de que o processo de subjetivação das masculinidades, não é mais simples que o feminino, como erroneamente atribuído às perspectivas psicanalíticas, ou mesmo que a diferença sexual se reduz ao ponto de vista anatômico (COELHO, 2013).

O eixo 2 "Estudos de gênero com foco ampliado", diz respeito aos estudos que debatem os estudos de gênero, utilizando a psicanálise como exemplos de vias de leituras e sobretudo, pela crítica da teoria. Entretanto, estes estudos não se aprofundam na especificidade das masculinidades. 
O eixo 3 "Estudos de gênero que contemplam a psicanálise de forma interdisciplinar", possui semelhanças ao eixo anterior, visto que são estudos de gênero. Contudo, contemplam as questões das masculinidades, e ainda se utilizam do discurso psicanalítico de forma interdisciplinar, à medida que a teoria é referida como uma referência de articulação com os estudos de gênero ou mesmo crítica, articulando aproximações e distanciamentos. O texto, "Masculinidade hegemônica: repensando o conceito repensando o conceito", dos autores Robert W. Connell e James W. Messerschmidt, se propõe a traçar uma origem do conceito de masculinidade, demostrando que seu uso não é reificado e nem essencialista.

A psicanálise é citada como uma teoria que influenciou o conceito de identidade de gênero, tendo uma representação importante para o campo dos estudos de gênero. Em relação às influências da teoria, citam os autores que a psicanálise se dedicou a: "temas do poder dos homens, do espectro de possibilidades do desenvolvimento do gênero e da tensão e contradição dentre masculinidades convencionais (CONNELL e MESSERSCHMIDT, 2013, p. 244).

O diálogo interdisciplinar com a psicanálise, demostra que os discursos feministas e de gênero são marcados pelo diálogo com a psicanálise, quase sempre, carregado de tensões e que evidenciam lacunas nas teorias psicanalíticas. Por outro lado, costumam reconhecer suas contribuições aos avanços destas temáticas. É interessante notar que todos os estudos selecionados também se fazem a partir de uma perspectiva relacional dos sexos, ou seja, não é possível falar em masculinidades sem tratar das feminilidades. Além disso, tanto os estudos de gênero quanto das principais correntes psicanalíticas, geralmente, procuram questionar os discursos biologizantes.

Sampaio e Garcia (2010), a propósito dos estudos de gêneros, apresentam tendências explicativas das identidades de gênero: universalista, relacional e plural, representadas principalmente por teóricas como Simone de Beauvior, Joan Scott e Judith Butler, respectivamente. Os autores demonstram com estas distinções que o 
campo dos estudos de gênero não se utiliza do uso de categorias universais para pensar masculinidades ou feminilidades, especialmente no que diz respeito aos trabalhos de Judith Butler. Neste sentido, desfoca-se do biológico para se compreender como os gêneros são constituídos socialmente. Em seguida, incluindo argumentos sobre a neurociência para demostrar leituras naturalizantes do gênero, Sampaio e Garcia (2010, p. 90) citam: "temos, então, aqui duas posições antagônicas, aquela que afirma ser a masculinidade uma "invenção" da cultura (BUTLER, 1990), e outra que afirma ser a masculinidade efeito de forças orgânicas inerentes aos sujeitos de sexo masculino (PINKER, 2006)".

A psicanálise, especificamente de escola francesa, é inserida, então, como um terceiro discurso. Sampaio e Garcia (2010), se referindo aos estudos lacanianos explicam que a construção da masculinidade se apoia nos destinos finais do Complexo de Édipo e na introdução da lei do pai pela metáfora paterna. Neste sentido, a linha lacaniana da psicanálise compreende que as trajetórias masculinas seriam fundamentadas na dinâmica triangular, nas dissoluções e identificações presentes nesse processo.

Portanto, as conclusões das masculinidades ou das feminilidades estariam apoiadas nos destinos da sexualidade infantil, desta forma, percebe-se que a abordagem pela psicanálise, especificamente de orientação francesa implica a ausência da distinção clara a partir do sexo como condição para o gênero (SAMPAIO e GARCIA, 2010).

A seguir, como forma de elucidação, o resumo de alguns temas encontrados nos artigos estudados: 
Figura 2 - resumo dos temas abordados nos artigos selecionados

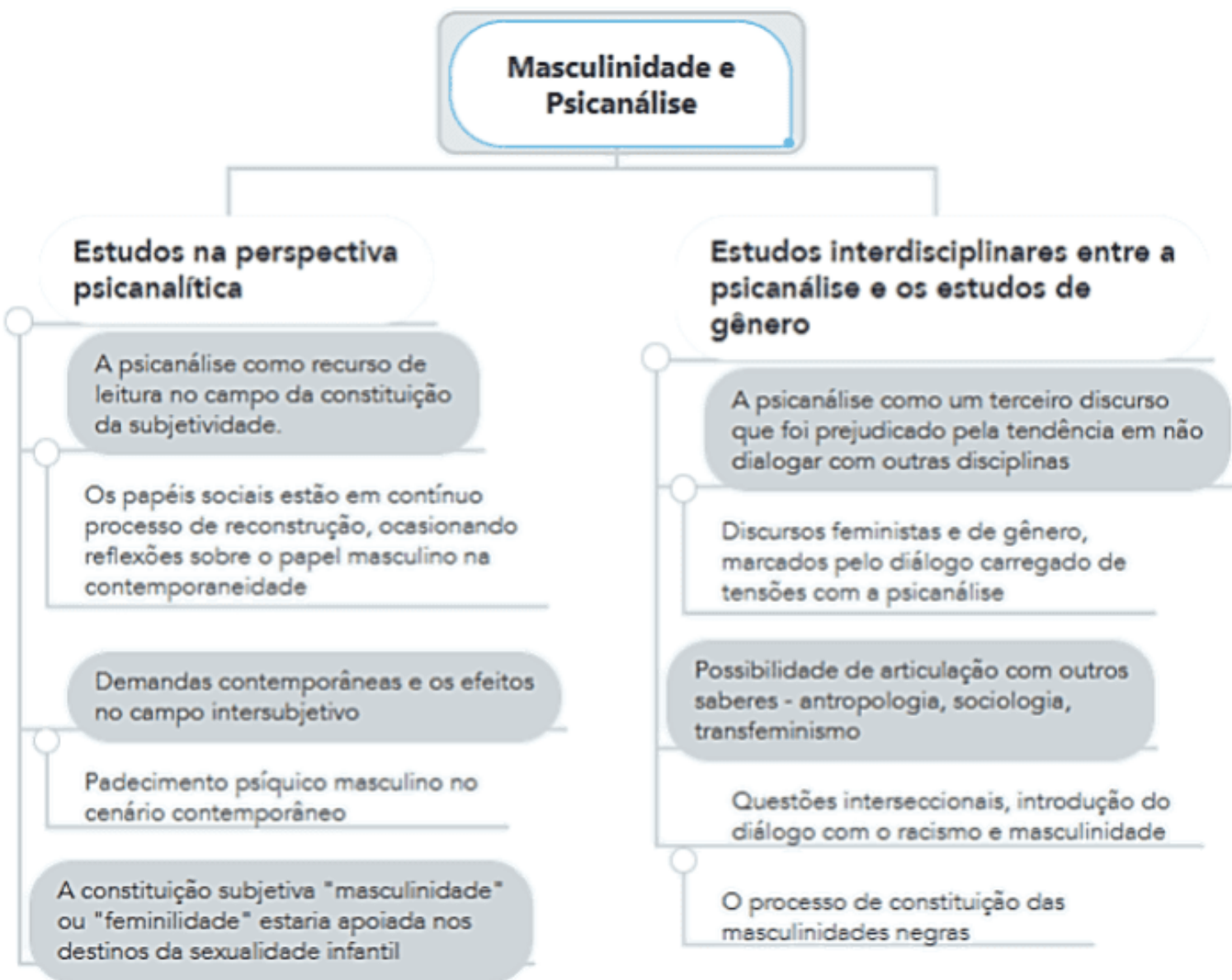

Fonte: Imagem elaborada pelas autoras.

Os trabalhos em Psicanálise e Masculinidade apresentam-se, portanto, via estudos na perspectiva psicanalítica e estudos interdisciplinares que contemplam as pesquisas com foco ampliado nas questões de gênero. Sob a perspectiva psicanalítica, a teoria vem sendo utilizada, portando, como um recurso de leitura para o campo das constituições subjetivas, bem como as transformações deste campo e os efeitos nos sujeitos. Sob a via interdisciplinar dos estudos, a teoria psicanalítica é identificada, principalmente, a partir dos diálogos carregados de tensões com os estudos feministas e de gênero, bem como a necessidade de articulações com outros campos de saberes. 


\section{CONSIDERAÇÕES FINAIS}

Diante da pertinência dos estudos que contemplem a constituição das subjetividades masculinas, pretendeu-se compreender de que maneira a psicanálise aborda a questão da masculinidade nas pesquisas recentes publicadas no Brasil. Desta forma, os três (3) eixos identificados como tendências temáticas: "estudos psicanalíticos no âmbito das masculinidades", "estudos de gênero com foco ampliado" e "estudos de gênero que contemplam a psicanálise de forma interdisciplinar", demonstram que, a psicanálise vem sendo utilizada na literatura como um discurso de influência nos crescentes debates sobre gênero e sexo, articulando aproximações e distanciamentos.

Especificamente sobre o eixo 1, percebe-se a partir da pesquisa realizada por este trabalho, que o estudo em masculinidade sob a perspectiva da psicanálise, sustentam a hipótese freudiana sobre a centralidade da sexualidade no desenvolvimento do psiquismo. Existe uma preocupação em examinar a constituição subjetiva do homem contemporâneo, e como as demandas atuais de repensar os significados das construções sociais dos sexos, interferem no campo intersubjetivo dos sujeitos, podendo ocasionar em padecimentos psíquicos. Visto que, surgem dificuldades ao lidar com essas novas demandas, e ainda, explicitar que a constituição subjetiva da masculinidade não pode ser considerada como menos complexas que os processos de subjetivações femininos.

Em contrapartida, ressaltaram-se o grande número de estudos que pretendem realizar o diálogo interdisciplinar com o considerado "terceiro discurso", apontando suas falhar na não abertura de diálogos com outras áreas do conhecimento. Percebe-se, nesse sentido, um atravancamento da psicanálise, ao mesmo tempo em que a teoria se dispõe à estudar as demandas contemporâneas, estas parecem não dialogar interdisciplinarmente. 


\section{REFERÊNCIAS}

BIRMAN, Joel. Sexualidade na contemporaneidade. Cadernos de Psicanálise. CPRJ, Rio de Janeiro, v. 40, n. 38, p. 137-159, jun. 2018. Disponível em <http://pepsic.bvsalud.org/scielo.php?script=sci_arttext\&pid=S141362952018000100009\&lng=pt\&nrm=iso >. Acesso em: 01 nov. 2020.

BRASIL. Ministério da Saúde. Banco de dados do Sistema Único de SaúdeDATASUS, Sistema de Informações de Mortalidade do Sistema Único de Saúde (SIM/SUS).

Disponível

em:

http://www2.datasus.gov.br/DATASUS/index.php?area=060701\#: :text=0\%20Siste ma\%20de\%20Informa\%C3\%A7\%C3\%B5es\%20sobre,de\%20gest\%C3\%A30\%20na \%20sa\%C3\%BAde\%20p\%C3\%BAblica. Acesso em: 01 nov. 2020.

COELHO, Bruno Alves. A feminilidade como uma posição de sujeito: uma abordagem lacaniana. Psicologia USP, São Paulo, v.24, n.1, pp.99-117, abr. 2013. Disponível em: < https://www.scielo.br/pdf/pusp/v24n1/v24n1a06.pdf>. Acesso em: 01 nov. 2020.

CONNELL, Robert W.; MESSERSCHMIDT, James W. Masculinidade hegemônica: repensando o conceito. Revista Estudos Feministas, Florianópolis, v. 21, n. 1, p. 241-282, jan. - abr. 2013. Disponível em: < https://www.scielo.br/pdf/ref/v21n1/14.pdf>. Acesso em: 01 nov. 2020.

COSSI, Rafael Kalaf; DUNKER, Christian Ingo Lenz. A Diferença Sexual de Butler a Lacan: Gênero, Espécie e Família. Psic.: Teor. e Pesq., Brasília, v. 33, e3344, jun. 2017. Disponível em: <http://www.scielo.br/scielo.php?script=sci_arttext\&pid=S010237722017000100404\&lng=en\&nrm=iso >. Acesso em: 21 Mar. 2021.

FÓRUM BRASILEIRO DE SEGURANÇA PÚBLICA. Violência doméstica durante a pandemia de Covid-19. São Paulo. 2020. Disponível em: 
https://forumseguranca.org.br/wp-content/uploads/2018/05/violencia-domesticacovid-19-v3.pdf. Acesso em: 01 de novembro de 2020.

FREUD, Sigmund. A feminilidade. In: FREUD, Sigmund. O mal-estar na civilização, novas conferências introdutórias à psicanálise e outros textos: (1930-1936). Tradução: Paulo Cesar de Souza. São Paulo: Companhia das Letras, v. 18, 2010.

FREUD, Sigmund. Algumas consequências psíquicas da diferença anatômica entre os sexos (1925). In: FREUD, Sigmund. O Eu e o Id "autobiografia" e outros textos (1923- 1925). Tradução: Paulo Cezar Souza. São Paulo: Companhia das Letras, v. 16, 2011.

GIDDENS, Anthony. Sociologia. Tradução: Alexandra Figueiredo et al. 6.ed. Lisboa: Fundação Calouste Gulbenkian, 2007.

GIL, Antônio Carlos. Como elaborar projetos de pesquisa. 4.ed. São Paulo: Atlas, 2007.

INSTITUTO DE PESQUISA ECONÔMICA APLICADA; FÓRUM BRASILEIRO DE SEGURANÇA PÚBLICA (Org.). Atlas da violência 2019. Brasília; Rio de Janeiro; São Paulo: IPEA; FBSP, 2019. Disponível em: https://www.ipea.gov.br/atlasviolencia/download/19/atlas-da-violencia-2019. Acesso em: 01 de novembro de 2020.

LAPLANCHE, Jean. O gênero, o sexo e o sexual. In: LAPLANCHE, Jean. Sexual: a sexualidade ampliada no sentido freudiano 2000-2006. Porto Alegre, RS: Dublinense, 2015.

LAPLANCHE, Jean; PONTALIS. Vocabulário da psicanálise. Tradução Pedro Tamem. 4.ed. São Paulo: Martins Fontes, 2001.

MOLINIER, Pascale; WELZER-LANG, Daniel. In: HIRATA, Helena et al. (org.). Dicionário Crítico do Feminismo. São Paulo: Editora UNESP, 2009. 
OLIVEIRA, Pedro Paulo. A construção social da masculinidade. - Belo Horizonte: editora UFMG, Rio de Janeiro: IUPERJ, 2004.

ORGANIZACIÓN PANAMERICANA DE LA SALUD. Masculinidades y salud en la Región de las Américas. Resumen. Washington, D.C.: OPS; 2019.

RAMOS, Altina; FARIA, Paulo M.; FARIA, Ádila. Revisão sistemática de literatura: contributo para a inovação na investigação em Ciências da Educação. Rev. Diálogo Educ., Curitiba, v. 14, n. 41, p. 17-36, jan - abr, 2014.Disponível em: < https://periodicos.pucpr.br/index.php/dialogoeducacional/article/view/2269/0>. Acesso em: 01 nov. 2020.

SAMPAIO, Ronaldo Sousa; GARCIA, Claudia Amorim. Dissecando a masculinidade na encruzilhada entre a psicanálise e os estudos de gênero. Psicologia em Revista, Belo Horizonte, v. 16, n. 1, p. 81-102, abr. 2010. Disponível em: < http://pepsic.bvsalud.org/scielo.php?script=sci_arttext\&pid=S167711682010000100007 >. Acesso em: 01 nov. 2020.

SCULOS, Bryant W. Who's Afraid of 'Toxic Masculinity?. Class, Race and Corporate Power: Vol. 5, Issue 3, 2017. np. Disponível em: http://digitalcommons.fiu.edu/classracecorporatepower/vol5/iss3/6. Acesso em: 01 nov. 2020.

SILVA, Fernanda Cesa Ferreira da; MACEDO, Mônica Medeiros Kother. A escuta do masculino na clínica psicanalítica contemporânea: singularidades de um padecer. Psicologia: Teoria e Pesquisa, Brasília, v. 28, n. 2, p. 205-217, abr - jun. 2012. Disponível em: < https://www.scielo.br/pdf/ptp/v28n2/09.pdf>. Acesso em: 01 nov. 2020. 


\section{APÊNDICE - REFERÊNCIA DE NOTA DE RODAPÉ}

3. 1) Hacia las mujeres y los niños (violencia, abuso de sustancias psicoactivas, infecciones de transmisión sexual, embarazos forzados, paternidad ausente y falta de corresponsabilidad en el hogar). 2) Hacia otros hombres (accidentes, homicidios y otros, transmisión del $\mathrm{VIH} / \mathrm{sida}$ ). 3) Hacia sí mismo (suicidio, accidentes, alcoholismo y adicciones, y enfermedades psicosomáticas).

Enviado: Abril, 2021.

Aprovado: Maio, 2021. 